\title{
Time-dependent opportunities in energy business: A comparative study of locally available renewable and conventional fuels
}

\author{
Athanasios I. Tolis *, Athanasios A. Rentizelas, Ilias P. Tatsiopoulos \\ School of Mechanical Engineering, Industrial Engineering Laboratory, National Technical University of Athens, Iroon Polytechniou 9 Str., 15780 Zografou, Athens, Greece
}

\section{A R T I C L E I N F O}

\section{Article history:}

Received 27 April 2009

Accepted 13 July 2009

\section{Keywords:}

Real options

Investment optimisation

Forecasting

Biomass

Natural gas

Carbon capture

\begin{abstract}
A B S T R A C T
This work investigates and compares energy-related, private business strategies, potentially interesting for investors willing to exploit either local biomass sources or strategic conventional fuels. Two distinct fuels and related power-production technologies are compared as a case study, in terms of economic efficiency: the biomass of cotton stalks and the natural gas. The carbon capture and storage option are also investigated for power plants based on both fuel types. The model used in this study investigates important economic aspects using a "real options" method instead of traditional Discounted Cash Flow techniques, as it might handle in a more effective way the problems arising from the stochastic nature of significant cash flow contributors' evolution like electricity, fuel and $\mathrm{CO}_{2}$ allowance prices. The capital costs have also a functional relationship with time, thus providing an additional reason for implementing "real options" as well as the learning-curves technique. The methodology as well as the results presented in this work, may lead to interesting conclusions and affect potential private investment strategies and future decision making. This study indicates that both technologies lead to positive investment yields, with the natural gas being more profitable for the case study examined, while the carbon capture and storage does not seem to be cost efficient with the current $\mathrm{CO}_{2}$ allowance prices. Furthermore, low interest rates might encourage potential investors to wait before actualising their business plans while higher interest rates favor immediate investment decisions.
\end{abstract}

(c) 2009 Elsevier Ltd. All rights reserved.

\section{Contents}

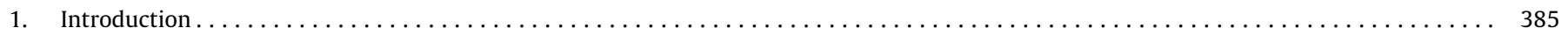

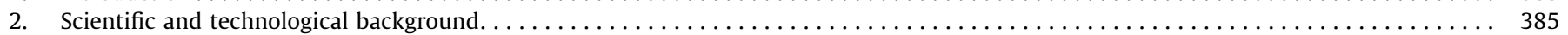

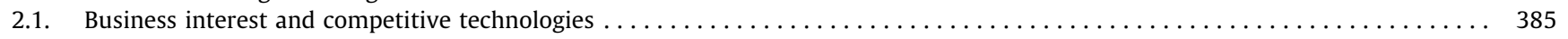

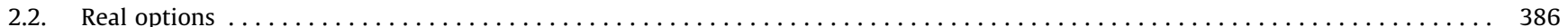

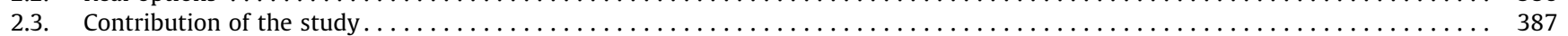

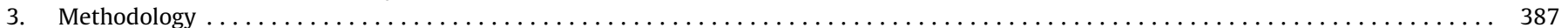

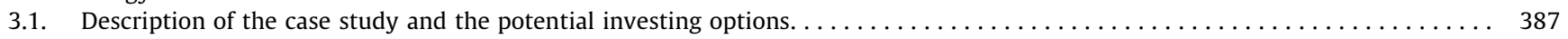

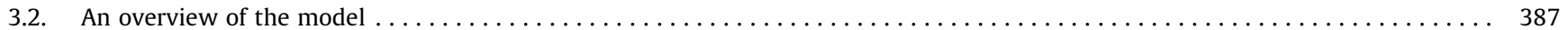

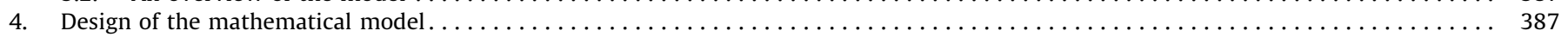

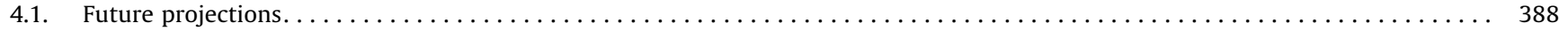

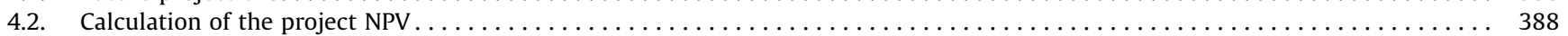

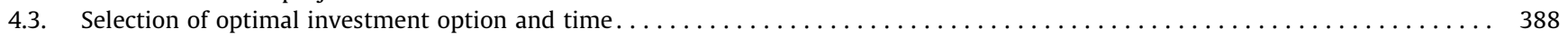

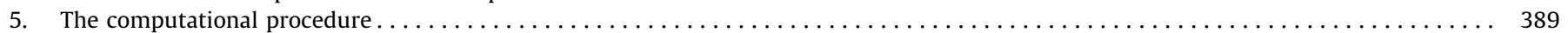

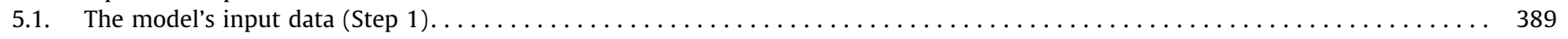

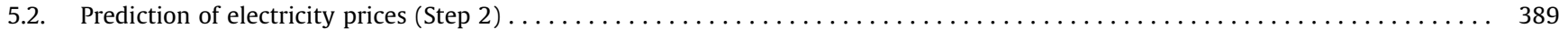

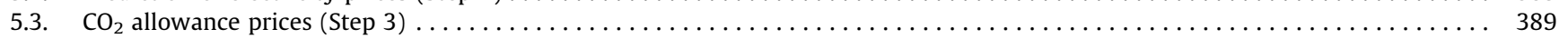

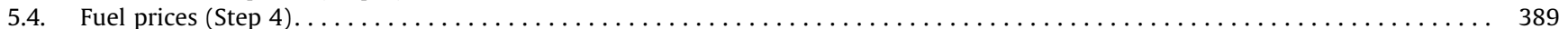

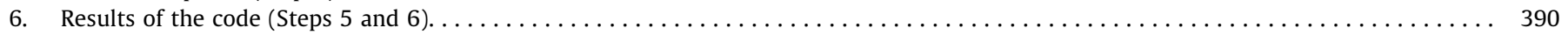

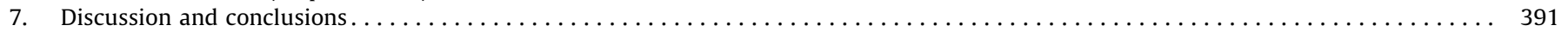

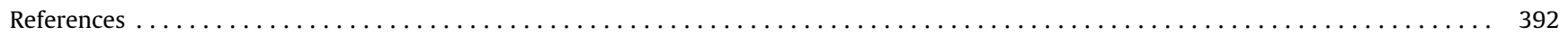

\footnotetext{
* Corresponding author. Tel.: +30 210 7722385; fax: +30 2107723571 .

E-mail address: atol@central.ntua.gr (A.I. Tolis).
} 


\begin{tabular}{|c|c|}
\hline \multicolumn{2}{|c|}{ Nomenclature } \\
\hline$c_{e}$ & electricity selling price $\left(€ / \mathrm{MWh}_{\mathrm{el}}\right)$ \\
\hline$c_{f}$ & fuel cost $\left(€ / \mathrm{MWh}_{\mathrm{f}}\right)$ \\
\hline$e_{f}$ & emissions factor of fuel (ton $\mathrm{CO}_{2} / \mathrm{MWh}_{\mathrm{f}}$ ) \\
\hline$n$ & efficiency factor (\%) \\
\hline$f_{\text {cap }}$ & capacity factor \\
\hline$F$ & fixed costs $\left(€ / \mathrm{MW}_{\mathrm{el}} /\right.$ year $)$ \\
\hline$V$ & variable costs $\left(€ / \mathrm{MWh}_{\mathrm{el}}\right)$ \\
\hline$c_{\mathrm{CO}_{2}}$ & $\mathrm{CO}_{2}$ allowance price (€/ton) \\
\hline$P_{\max }$ & maximum load of installed capacity $\left(\mathrm{MW}_{\mathrm{el}}\right)$ \\
\hline$P_{\text {cum }, i, v}$ & $\begin{array}{l}\text { cumulative installed capacity (worldwide, of tech- } \\
\text { nology } i \text {, in year } v \text { ) }\end{array}$ \\
\hline$C(t)$ & $\begin{array}{l}\text { time function of power-averaged algebraic cash } \\
\text { flow }(€ / M W h)\end{array}$ \\
\hline$d t$ & time differential (day) \\
\hline$F B F$ & algebraic balance of annual cash flow (€/year) \\
\hline ir & interest rate (\%) \\
\hline$b_{i}$ & learning rate for a power plant type $i$ \\
\hline$N P V_{i, v}$ & $\begin{array}{l}\text { net present value for a power plant of type } i \text {, } \\
\text { commissioned at time } v(€)\end{array}$ \\
\hline$C I_{i, v}$ & $\begin{array}{l}\text { investment (capital) cost for a power plant of type } i \text {, } \\
\text { commissioned at time } v(€ / \mathrm{kW})\end{array}$ \\
\hline$T$ & operational life-time (years) \\
\hline ID & investment decision time (years ahead from today) \\
\hline$v$ & $\begin{array}{l}\text { setup and commissioning time (years ahead from } \\
\text { today) }\end{array}$ \\
\hline$i$ & indicator of power plant type (technology - fuel) \\
\hline
\end{tabular}

\section{Introduction}

Economic efficiency and sustainable development are admittedly closely linked. Concerning energy production, private investors are facing important dilemmas regarding the fuel type and the related technologies that they should invest in. Power production is also believed to be a high-risk business. Not only the innovations of emerging power generation methods but also the uncertainties of electricity and fuel prices contribute to the establishment of an obscure and unstable business environment and may have a direct impact on the feasibility as well as on the scale and the location of an energy-related investment. Furthermore, environmental constraints as well as the implementation of the European emissions trading system (EU-ETS) impose additional risks and implications that should be carefully considered. On the other hand, electricity markets have gone through a deregulation process, which has introduced competition in a formerly state-regulated sector. Therefore, the planning for engagement in the new energy market arena should focus not only on economic considerations, such as the minimisation of production costs, but also on strategic fuel selection and minimisation of $\mathrm{CO}_{2}$ emissions. These issues, together with the recent rapid changes of legal status aiming at deregulation, contribute to the need for revised decision making processes, more than ever crucial for successful investments.

Greece stands as a typical example of a geographical area, well favored to bear high levels of renewable energy potentials. A big part of central Greece, Thessaly, is an agricultural area where more than $1500 \mathrm{~km}^{2}$ are cultivated with cotton; certainly, the biggest in Greece and one of the biggest in Europe. The key-players of the local cotton supply chain - mainly cotton ginneries - might be interested to invest in energy production based on cotton-stalks biomass in order to create a counterbalance for their grid electricity expenses. On the other hand, natural gas (NG) has been strategically selected by the Greek State as the next generation base-load fuel and appears to have a constantly increasing penetration in the domestic energy market. This conventional energy source is characterised by relatively low emissions, minimum losses and stable pressure and flow rate conditions. Moreover, its distribution network is consisted of a main pipeline, which traverses Eastern Greece including the target area of Thessaly as well as the biggest industrial areas which are located between Thessaly and Attica. It is noted that the industries located in this geographical area constitute the growth workhorse of the Greek economy.

The starting point of the present study is an industrial user located in Thessaly, who is considering a power-production investment. The following two options appear to be more feasible:

1. Exploiting the local renewable energy source (cotton-stalk biomass).

2. Investing in a low-emission, low-cost, conventional fuel (natural gas).

Alternatively, there is a third option, which does not include any future business plans:

3. Maintain the current status (no investment-keep paying for grid electricity).

Finding the most attractive option is the primary objective of the present study. An integrated computational model has been created with a "real options" perspective. The traditional ways of deterministic financial analysis of investments, like the Discounted Cash Flow (DCF) analysis, are not capable of handling adequately the increased uncertainty appearing in the prices of electricity, fuels and $\mathrm{CO}_{2}$ allowances [1,2]. This means that the above mentioned investment options should be compared, considering not only the current status of the energy market and the related business environment, but also their future prospects and evolution. This imposes a factor of uncertainty, and therefore an additional option is investigated: "wait before investing". Hence, the goal is to find the highest-NPV investment, as well as its optimal realisation time. A major milestone of the model is to simulate and correlate the variables under uncertainty so that their forecasting would take into account their functional dependencies. In order to accomplish the above milestones and objectives, some advanced computational techniques had to be implemented, to overcome the difficulties arising from the nonlinear interaction of the various stochastic variables.

The present study is structured in brief as follows: In Section 2, a literature review is presented. In Section 3 an overview of the model is given while details of the mathematical and computational model are provided in Sections 4 and 5, respectively. Section 6 includes the results of the model's implementation. Finally, in Section 7 a critical analysis is presented with suggestions on strategic interventions and sustainability impact of the investigated energy resources and their related power-production technologies.

\section{Scientific and technological background}

\subsection{Business interest and competitive technologies}

Natural Gas Combined Cycle (NGCC) and related technologies have been mature enough due to almost three decades of experience and implementation on power production. Numerous 
plants have been installed all over the world. NGCC operates in two discrete phases using a combination of two thermodynamic cycles: gas-turbine and steam-turbine. After the combustion of natural gas, a gas-turbine exploits flue-gas enthalpy for power generation (1st phase). The remaining gas enthalpy is then exploited by an HRSG (heat recovery steam generator) in order to run a steamturbine which produces additional electricity (2nd phase), thus increasing the overall efficiency of the power plant. $50 \mathrm{~Hz}$ gasturbines may have a capacity in the range $20-400 \mathrm{MW}_{\mathrm{el}}$ while steam-turbines may have a capacity in the range 6-200 $\mathrm{MW}_{\mathrm{el}}$. As a rule of thumb it may be considered that gas-turbines represent the $66 \%$ of the plants' output [3]. NGCC is a flexible method for natural gas exploitation achieving significantly high overall HHV efficiency (Higher Heating Value), up to $60 \%$. In some studies like [4] it is reported that NGCC capital costs may be as low as $550 \$ / \mathrm{kW}$ although this seems to be a rather optimistic value. In the same study, the fuel costs are considered to be $3.46 \$ / G J$ and operational-maintenance costs (O\&M) are $3 \$ / M W h$. Natural gas plants emit 95 and $83 \%$ fewer metric tons of $\mathrm{SO}_{x}$ and $\mathrm{NO}_{x}$, respectively, than an average coal plant and less than one-half of the $\mathrm{CO}_{2}$ emitted by a conventional coal fired plant [5].

Gasification of biomass on the other hand is a competitive technology which produces hydrogen reach gases (synthesis-gas or syngas), suitable for a single gas-turbine system, while it separates tar and char. The syngas is usually consisted of a $\mathrm{CO} / \mathrm{H}_{2}$ mixture which is able to be burned in a combustion chamber and the resulting flue-gas enthalpy is used to run a gas-turbine, thus producing electricity with an expected efficiency of 35\% [6]. Alternatively, supercritical steam-turbines might be used especially for the case of solid fuel mixes. The efficiencies reported for projects based on supercritical steam-turbine technology, are close to the levels of $40 \%$, due to the utilisation of materials specifically manufactured for "smart" strengthening against corrosion in very high temperatures [7]. This technology is characterised by the advantage of high MTBFs (Mean Time Between Failures) compared to the gasification technology and accompanied syngas usage. The syngas combustion usually results in short gas-turbine MTBFs mainly due to micro-parts which contribute to turbine blades corrosion. Consequently, significantly higher maintenance costs are reported and moreover, the availability falls significantly resulting to lower capacity factors [6].

IGCC (Integrated Gasifier Combined Cycle) is an emerging power-production technology, consisted of a gasifier and a combined cycle for power production. IGCC's individual components are mature technologies as stated above but integrated IGCC systems are not yet so commonly installed. Historically, power generating systems with a capacity higher than $100 \mathrm{MW}_{\mathrm{el}}$ based on biomass feed stocks, were deemed infeasible because of the associated feed requirements. However, the use of advanced combined cycle technology reduces the fuel requirements to manageable levels because of the increases in generating efficiency. Some elaborated studies have been carried out investigating the feasibility of IGCC technology for biomass exploitation (Biomass Integrated Gasification Combined Cycle or BIGCC projects). In [8], an extensive study of BIGCC systems is presented, in the range of 56-132 $\mathrm{MW}_{\mathrm{el}}$. The net HHV efficiencies reported on that study fluctuate in the range $36-39.7 \%$. The capital costs fluctuate in the levels of $1300-1700 \$ / \mathrm{kW}$ and the cost of electricity (COE) is estimated close to $0.054-0.063 \$ / \mathrm{kWh}$ (constant prices assuming amortisation at $4.5 \%$ interest rate, over 30 years of operational life-time with a capacity factor 0.8 ). Rhodes and Keith [4], analysed also, important economic aspects of BIGCC systems in the range of $110-149 \mathrm{MW}_{\mathrm{el}}$ and produced some very interesting results. In this study, a BIGCC plant without a $\mathrm{CO}_{2}$ capture and storage (sequestration) system (CCS), with an estimated HHV net efficiency of $34 \%$ and net generation $\sim 149 \mathrm{MW}_{\mathrm{el}}$, may have a capital cost of $1250 \$ / \mathrm{kW}$ and annual O\&M costs $100 \$ / \mathrm{kW}$, while its COE might be as low as $0.059 \$ /$ $\mathrm{kWh}$. In the same study a BIGCC plant with CCS and net generation of $123 \mathrm{MW}_{\mathrm{el}}$ might present a lower HHV efficiency ( 28\%), higher capital costs (approximately $1730 \$ / \mathrm{kW}$ ) while its COE could be as high as $0.082 \$ / \mathrm{kWh}$ due to the high CCS costs. In a more recent study [9], higher net efficiencies are envisaged for the close future due to ongoing improvements on IGCC technology and some interesting data for IGCC plants already installed are listed within a capacity range 100-545 $\mathrm{MW}_{\mathrm{el}}$. The assumptions for IGCC technology indicate capital costs $\sim 1450 \$ / \mathrm{kW}$, and net HHV efficiency in the range $40-50 \%$ provided that a CCS system is not installed. In the case of IGCC/CCS the capital costs rise to the levels of $2000 \$ / \mathrm{kW}$.

Biomass as well as NG are both eco-friendly fuels compared with other fossils like coal or lignite. Certainly, biomass is a renewable source contributing significantly to sustainability but NG might become also an attractive solution for potential investors. Economic efficiency of bioenergy may have a significant impact on sustainable development, especially in a region which depends economically on seed-cotton life cycle. Cotton-stalk biomass is a zero $\mathrm{CO}_{2}$ emission fuel which requires careful procedural and organisational analysis in order to design its supply-chain network. Logistics costs contribute significantly to the costs of a biomass-fuelled power plant as can be seen in [10], where a logistical analysis of cotton-stalk biomass in Thessaly has been carried out. The engagement of multiple biomass sources is a very promising concept for reducing the logistics costs and revitalising degraded agricultural areas, while its potential advantages as well as limitations have been modelled in [11].

\subsection{Real options}

In investment problems, some variables might present a volatile time pattern. Older DCF methods were exclusively used in the past without gaining insight in the non-stationary and highly unstable profile of modern investment games. Trigeorgis [12] presented in 1996 the real options (RO) concept, which is a more elaborate type of investment analysis and deals with the future projections of basic parameters like expected incomes and expenses. Suitable probabilistic techniques and forecasting methods - presented by Dixit and Pindyck [13] - may fit in RO studies in order to deal with uncertainties. A variety of mathematical and computational models have been recently created using RO analysis and concerning energy-related investments. One could distinguish two separate classes of models based on RO analysis: (i) those who suggest investment options for private energyrelated businesses [14,15] and (ii) those dealing with policy interventions and suggesting State-originating power licensing procedures like in [16] and [2]. The present study implements the "real options" concept for private investments, and therefore it should be classified to the first (i) category of financial modelling.

More specifically, the investment costs are considered to be a logarithmic function of time according to the learning-curves technique [2,17] so that the competitiveness and experience acquired by previous projects is taken into account. The $\mathrm{CO}_{2}$ trading scheme, activated recently in Europe through the EU-ETS has become a reality and energy-related business has been greatly affected by it. The $\mathrm{CO}_{2}$ allowance price - a rather volatile function of time - is projected to the future using appropriate forecasting methods which will be described in the mathematical model. Fuel costs may also be characterised by unstable profiles mainly due to endogenous dependences on inflation rate. For example, their logistical costs include the transportation costs which may be linked to personnel expenses or oil price variations. Finally the incomes, which in our case come from electricity selling to the national grid, present a non-stationary time-path and therefore, 
are forecasted from historical data, provided that a fossil fuel is utilised for power production. In the case of power-production based on renewable sources, the Greek law defines a fixed price and a price evolution algorithm - contractually agreed - for every $\mathrm{kWh}$ sold to the grid.

Among the most basic components of a real option study is the forecasting computational algorithm. A variety of existing algorithms like ARMA and ARIMA models [18] and GARCH type of models $[19,20]$ are mainly used for mid-range forecasting tasks. The random walk methods like the Ito process are generalised stochastic Wiener processes with normally distributed jumps which usually succeed in producing reasonable results within sufficiently shorter computational times, and have been used for electricity and fuel price projections [14,15]. The Geometric Brownian Motion (GBM) [21] is one of the most common random walk models, mainly used for mid-range forecasts. It is usually simulated with an Euler-Marujama solver [22] while a MonteCarlo approximation [23] is used to average the solutions set.

\subsection{Contribution of the study}

This work might prove to be a pilot reference for similar comparative studies, provided that historical data are available for target fuel prices and their related power-production technologies in order to reveal their functional correlations. Apart from the results presented in this article, the methodological contribution of the study may be summarised in the following combinations of key-points:

1. A time-dependent comparison of NGCC with biomass-fired plants is performed in terms of economic efficiency and within the frame of a "real options" method.

2. An impact assessment of $\mathrm{CO}_{2}$ trading to energy investments and business plans is performed, including the emerging carbon capture and storage (CCS) technology and relevant applications.

3. Non-stationary time projections of capital costs are attempted using appropriate learning rates, thus reflecting competitiveness and cumulative experience on similar projects for each technology.

\section{Methodology}

\subsection{Description of the case study and the potential investing options}

An investment intention for an IGCC unit or alternatively a single supercritical HRSG, with net efficiency 40\% which would be able to exploit the entire amount of Thessaly's cotton-stalk biomass, requires a total plant capacity in the range of 100$120 \mathrm{MW}_{\mathrm{el}}$. This is a direct output of the cotton-stalk HHV - which is close to $14,000 \mathrm{~kJ} / \mathrm{kg}$ - and its production per area unit which is moderately high, 300 ton $/ \mathrm{km}^{2}$ in wet basis [10]. There are many key-players willing to engage in the energy market not only in order to serve their own energy needs, but also to have a chance for profitable business opportunities. Such potential investors - like ginnery or seed-oil factory owners - might wish to exploit local biomass (cotton-stalk residues) not only because they are already a part of its supply chain, but also because they are its main industrial end-users. Nonetheless, other users might be interested, such as hotels, big hospitals, farms, and factories with significant energy needs like a local cement producing factory which is currently fuelled by old tires. On the other hand, natural gas pipelines have recently crossed Thessaly and constitute a tempting alternative fuel. The HHV of natural gas is significantly higher than that of biomass (37-41 MJ/m³), which is twice the HHV of coal gas, and eight times the HHV of commercial producer gas [24,25]. Simultaneously, its procedural, organisational and logistical requirements are moderate, since only the connection to the main distribution network is needed-provided of course that it has been already installed. It is emphasised that within the frame of this study, the business interest focused on electricity selling to the grid and not on auto-producer activities.

Concerning the EU-ETS, two different scenarios for the $\mathrm{CO}_{2}$ allowances allocation policy have been considered:

- No free allowances after the year 2012.

- The $\mathrm{CO}_{2}$ allowances are always free (their price is always equal to zero).

The second scenario is analysed in order to assess the impact of the EU-ETS in the investigated options.

\subsection{An overview of the model}

The starting point is the target plant's capacity. This is a feed stock driven calculation, which is based on the hypothetical exploitation of the entire cotton-stalk biomass of Thessaly and thus determines a biomass-fired plant whose capacity is approximately $100 \mathrm{MW}_{\mathrm{el}}$. Apparently, the power plant capacity should be the same for both fuel types so that a comparison would be feasible. Alternatively, and in the present study, the starting point is a fixed investment cost equal to that required for the above-mentioned biomass-fuelled plant. In that case, the capacity of the other investigated plant types is modified accordingly.

Electricity, fuel, and $\mathrm{CO}_{2}$ allowance prices are then forecasted by solving appropriate SDEs with an Euler-Marujama solver which embeds a Monte-Carlo subroutine. The forecasted numerical data "feed" the next step of the model, which is an attempt to (i) find an optimum investing time-point and (ii) select the most interesting investing option. This process is performed using a time iterative procedure. An NPV calculation is repeatedly shifted by 1 -year steps, meaning that the decision for investment may be postponed for as many years as needed for the investment to be more profitable. By this way, an array of the project NPVs is created supposing that the hypothetical investment will take place during sometime in the close future (within the next 15 years). The optimality is determined by selecting the maximum NPV among the 15 years decision period. Emission's trading costs and related revenues (in the biomass/CCS plants) are embedded in the iterative procedure as contributors to the financial balancing function. The investment costs are calculated using the method of learning curves, so that competitiveness and experience acquired by previous projects are reflected to their timedepended calculated values.

The model is flexible and the modification of input data is easy, thus requiring short time for switching between case studies. Each run can analyse a case study comprised of four different powerproduction technologies and/or associated fuels which in the present work are: (a) biomass-fired plant without CCS, (b) biomass/CCS, (c) NGCC without CCS, and (d) NGCC/CCS. A fifth option is also calculated which is the AS-IS status of the potential investor (i.e. no investment; using grid electricity). In the next paragraphs, the mathematical model is described analytically with details on technical aspects.

\section{Design of the mathematical model}

The essential idea is based on the "real options" concept: Instead of comparing different investments using the traditional NPV criterion (prone to immediate investment decisions), one could alternatively investigate the optimal time for investment and engage it as an independent unknown variable. This type of investment analysis introduces a stochastic nature which might shed some light on crucial aspects: 
(i) Should an investor wait before realising his/her business plan or not?

(ii) How much time should he/she wait?

(iii) What kind of an investment could prove to be the most promising?

The road map to construct such a model comprises of the following tasks.

\subsection{Future projections}

A random walk type simulation has been used in this study in order to deal with the uncertainties imposed: the Geometric Brownian Motion (GBM). The assumption that the electricity and fuel price volatilities are normally distributed [21] has been an additional argument for the utilisation of a GBM model. The stochastic differential equation (SDE) of the GBM model was simulated using an Euler-Marujama type solver [22]. A MonteCarlo subroutine [23] was then used in order to average the multiple sets of forecasted variables. Typically, 100 solutions are averaged in order to produce a mean SDE solution. The volatility patterns of the different fuel prices should be mathematically correlated since their past correlation can strongly impact their future evolution [15]. The linkage of biomass price to NG price should be investigated, since they both depend on oil prices, though to a different extent [10]. The same stands for the volatility patterns of electricity prices and demanded loads. The random walk approximation method used in this study allows the simulation of generalised multivariate stochastic processes, and provides flexible and powerful simulation architecture. Parameters like mean drift, correlations and standard deviation are generated by the past data. The procedure supports general nonlinear relationships commonly found in SDE simulations. These paths, driven by vector-valued Brownian Motions could be easily simulated within short computational times. This kind of simulation approximates the underlying multivariate continuous-time process using vector-valued SDEs, which are described in Appendix A.

\subsection{Calculation of the project NPV}

The previously forecasted prices contribute either as incomes or expenses to the financial balance function (FBF) which is calculated algebraically on a day-by-day basis. The integral of the daily FBFs is then calculated for each year of plant operation. In mathematical formulation, the annual cash flow of a power plant is given by Eq. (1):

$F B F=P_{\max } \cdot f_{\text {cap }} \cdot \int C(t) d t-F \cdot P_{\max }$

The time differential $(d t)$ is assumed to be equal to 1-day interval. Within the context of EU-ETS implementation, the algebraic balance of the daily cash flows is calculated by subtracting the operational expenses of the power plant (fuel costs, $\mathrm{CO}_{2}$ costs, maintenance and other variable costs) from the electricity sales incomes to the national grid. This can be seen in the following Eq. (2):

$C(t)=c_{e}(t)-\frac{c_{f}(t)}{n}-\frac{e_{f}}{n} c_{\mathrm{CO}_{2}}(t)-V(t)$

The costs for the emissions trading correspond to the expenses of obtaining the required emission allowances for conventional power plants, whilst the revenues correspond to the incomes from trading the emission allowances generated by using biomass fuels and CCS systems. In case of negative $\mathrm{CO}_{2}$ emissions - a consequence of CCS utilisation in a biomass-fired plant - the
Eq. (2) is still valid provided that input $\left(e_{f}\right)$ is modified accordingly (i.e. negative $e_{f}$ ). On the other hand, if a biomass-fired plant without CCS is the case, neutral $\mathrm{CO}_{2}$ emissions lead to $e_{f}=0$. Considering Eq. (1) as the integral of daily cash flows for 1 year, its full formulation - taking into account Eq. (2) - becomes:

$$
\begin{aligned}
F B F(k)= & P_{\max } \cdot f_{\text {cap }} \cdot \int\left(c_{e}-\frac{c_{f}}{n}-\frac{e_{f}}{n} c_{\mathrm{CO}_{2}}-V\right) \mathrm{d} t-F \cdot P_{\max }, \\
& \forall k \in(v, v+T)
\end{aligned}
$$

The annual integrals calculated by Eq. (3) are given in nominal prices, but they are converted to present values (PV), using an appropriate constant interest rate in order to be comparable. Then, they are summed up, thus resulting to an aggregate project NPV which accounts for its entire operational life-time. The algebraic sum of annual cash flow PVs is calculated for the years foreseen to be the total operational life-time of each plant, using the following Eq. (4):

$N P V_{i, v}=\sum_{k=v}^{T+v}\left[F B F(k) \cdot \frac{1}{(1+i r)^{k}}\right]-C I_{i, I D}$

The above procedure is carried out iteratively assuming progressively advanced time of investment decision (ID time). The time-step between iterations equals to 1 year and each iteration is repeated for all fuel-plant combinations (biomass and natural gas fired plants with or without CCS).

The investment costs $\left[C I_{i, v}\right]$ of a power plant type $(i)$, commissioned in the year $(v)$, depend on technical advances arising from long periods of cumulative experience on construction of such power-production units. This fact is expressed by the learning-curves methodology [26] which has also been adopted in [17] and [2] and can be mathematically formulated as follows:

$C I_{i, I D}=C I_{i, 2009} \cdot\left(\frac{P_{\text {cum }, i, I D}}{P_{\text {cum }, i, 2009}}\right)^{\log _{2}\left[1-b_{i}\right]}, \quad \forall i$

The investment expenses of year 2009 are used as a reference value, while curve fitting has been applied in order to construct a continuous time relationship of global cumulative installed capacities evolution [27]. As stated before, the optimal Investment Decision time (ID), is an unknown to be found by the computational procedure. Actually, biomass and NG-fired plants appear to have similar construction (lead) times. They are usually commissioned within 3 years of their construction initiation. The ID time denotes the timing of investment decision, which is the starting point for construction, setup and commissioning of the investment. Therefore, it can take values in a range of 15-year time-period starting from 2010 and extending to the year 2025. Hence, an additional equation should provide a relationship between the ID time and the time of setup and commissioning completion $(v)$ which coincides with the initiation of cash flow activity. Based on the above, the required relationship is given by the following Eq. (6):

$v=I D+3$

\subsection{Selection of optimal investment option and time}

The final matrix of results is split in 5 columns and 15 rows of expected NPVs $[E(N P V)]$. Each column corresponds to the five investigated options: ( $a$ and $b$ ) invest in local biomass with and without a CCS system installed, (c and d) invest in NG with and without a CCS system installed and (e) remain to the current status. Each row corresponds to the $[E(N P V)]$ produced by assuming different ID times in the range (2010-2025). The matrix element with the maximum NPV is the requested result; its column 
corresponds to the most interesting fuel and associated powerproduction technology while its row corresponds to the optimal ID time point (years ahead from today).

\section{The computational procedure}

The computational procedure applied for the solution of the problem is based on the tasks described above, on the design of the model. It can be summarised in the following steps:

Step 1. Determination of problem's inputs and technological details, such as: setup periods, lead time (construction), operational life-time, basic investment and operational costs, capacity factors, etc.

Step 2. Prediction of electricity selling price to the grid using the GBM method.

Step 3. Prediction of $\mathrm{CO}_{2}$ allowance prices using a GBM SDE.

Step 4. Prediction of correlated fuel prices using the GBM method and appropriate correlation of their historical data.

Step 5. Calculation of aggregate project NPV for any fuel-plant combination and any ID time.

Step 6. Selection of the optimal project NPV as well as of the optimal ID decision time.

\subsection{The model's input data (Step 1)}

Inflation rate, interest rate and time periods of the study constitute the basic inputs of the model. The time periods are split in three discrete parts: (a) ID time, (b) construction commissioning and setup time, and (c) operational life-time. In the present case study, 15 (max), 3 and 32 years were allocated for these periods, respectively. As has been stated before, the ID time may take values in the range 1-15 years. The inflation rate is assumed to be $3 \%$, close to the current mean average of inflation in Greece, while the interest rate is assumed to be $8 \%$ including the inflation rate and a moderate technological risk. Another set of inputs necessary for the model is related with the investigated technologies and financial data. The entire field of technology related inputs needed for the iterative computational procedure is presented in Table 1.

\subsection{Prediction of electricity prices (Step 2)}

Electricity - being a product with a rather inelastic behaviour does not usually present demand patterns severely influenced by prices fluctuation except in rare circumstances. Its time-evolution path usually follows the actual social needs. In an effort to reveal such possible correlations and thus to obtain more accurate forecasts of prices' time-series, an additional forecasting was necessary to be done: that of electricity demand. The historical data of actual loads and System Marginal Prices (SMP) were acquired by the Hellenic Transmission System's Operator (HTSO S.A.) [28]. It is noted that SMP data actually constitute the payments realised by HTSO S.A. to conventional electricity producers. The historical data were available on an hourly basis for the time-period 2001-2008, but a mean daily average was calculated and finally used. As stated in the description of the mathematical model, an Euler type solver augmented by a Monte-

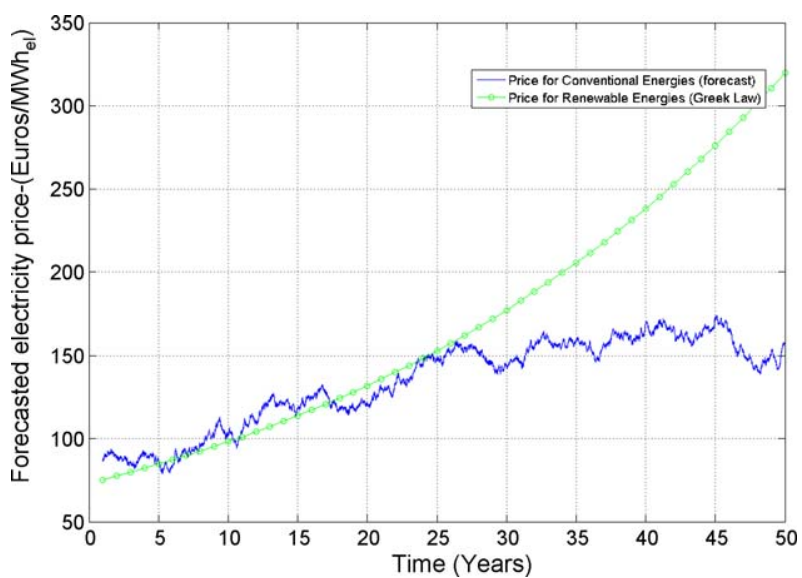

Fig. 1. Electricity price forecasts (conventional energies) and regulation (renewable energies).

Carlo procedure has been used to produce multiple simulations of a GBM type SDE for the years 2009-2059 and average them in order to obtain a single valid solution. The volatile forecasts of SMPs can be seen in Fig. 1 together with the nominal prices foreseen by the Greek Law for renewable power producers.

The standard deviation for the historical data of SMPs has been calculated equal to 20.8801 while its mean drift was 0.0166. A correlation coefficient has been derived from historical data of SMPs and loads using the Pearson's formula, in order to produce correlated stochastic differentials for the two variables. The calculated coefficient (0.5402) indicates a moderate correlation.

\section{3. $\mathrm{CO}_{2}$ allowance prices (Step 3)}

The $\mathrm{CO}_{2}$ allowance prices contribute to the system's expenses and revenues as seen in Eq. (1). These prices have been simulated using a GBM-type SDE with mean drift and standard deviation estimations 0.0210 and 0.1400 , respectively, derived from allowance prices historical data (Point Carbon [29]). The forecasted $\mathrm{CO}_{2}$ allowance prices can be seen in (Fig. 2):

\subsection{Fuel prices (Step 4)}

The historical data of natural gas prices [30] cover the time period 2001-2008 and provide the necessary information about the statistical parameters required by the GBM simulation (mean drift, standard deviation). Concerning the biomass price of the same period, the technique established in [10] was applied. With this method, the Reverse Logistics costs of the entire supply-chain are calculated via a Holistic Activity Based Costing (ABC) procedure. A mean drift - equal to the inflation rate - is further applied in order to reconstitute the biomass price evolution until the year 2059. This was done by simulating the GBM type SDE (Eq. ( $\left.2^{*}\right)$ of Appendix A). A mean solution was computed after 100 different trials within the frame of an iterative Monte-Carlo simulation using correlated stochastic differentials as explained in the description of the mathematical model. In an effort to identify the correlation between the prices of cotton-stalk biomass and

Table 1

The input data for the computational model.

\begin{tabular}{|c|c|c|c|c|c|c|}
\hline Power plant/fuel type & $\begin{array}{l}\text { Capital cost } \\
\text { (for 2009) }(€ / \mathrm{kW})\end{array}$ & $\begin{array}{l}\text { HHV } \\
\text { efficiency }\end{array}$ & $\begin{array}{l}\mathrm{CO}_{2} \text { emissions } \\
\text { (ton/ } / \mathrm{MWh}_{\mathrm{f}} \text { ) }\end{array}$ & $\begin{array}{l}\text { Fixed costs } \\
(€ / \text { kW/year) }\end{array}$ & $\begin{array}{l}\text { Variable costs } \\
\left(€ / \mathrm{MWh}_{\mathrm{el}}\right)\end{array}$ & $\begin{array}{l}\text { Learning } \\
\text { rate }\end{array}$ \\
\hline Biomass/no CCS & 1200 & 0.34 & 0 & 5.8 & 10.5 & 0.05 \\
\hline Biomass/CCS & 1730 & 0.28 & -0.200 & 6.5 & 13.65 & 0.05 \\
\hline NGCC/no CCS & 600 & 0.51 & 0.240 & 2.6 & 2.3 & 0.15 \\
\hline NGCC/CCS & 1190 & 0.44 & 0.024 & 4.3 & 3.8 & 0.15 \\
\hline
\end{tabular}




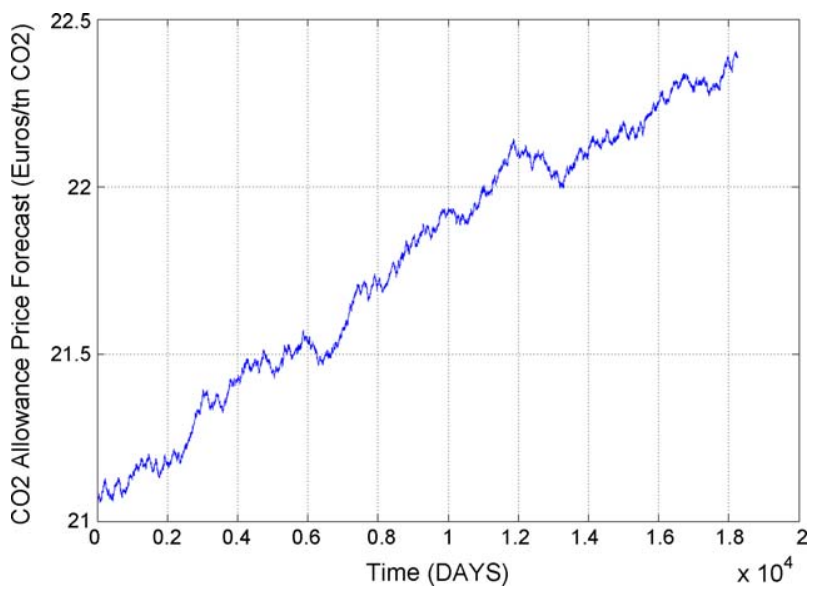

Fig. 2. $\mathrm{CO}_{2}$ allowance price forecasts.

Table 2

Stochastic differentials' correlation coefficients of fuel prices extracted from historical (NG-oil) and analytically computed (biomass) values.

\begin{tabular}{lccc}
\hline & Oil & Natural gas & Biomass \\
\hline Oil & 1 & 0.8395 & -0.0645 \\
Natural gas & 0.8395 & 1 & -0.511 \\
Biomass & -0.0645 & -0.511 & 1 \\
\hline
\end{tabular}

natural gas, their correlation coefficient is computed based on their past observed prices and on past oil prices. The correlation coefficients are presented in Table 2. A strong correlation between NG and oil prices can be noticed while the correlation between oil and biomass prices is weak.

The correlation coefficients are then used for future prediction of fuel prices. The resulting fuel price evolution is presented in the following graph (Fig. 3). It is emphasised that the fuel prices include their mining and/or harvesting costs, their logistical costs (transportation, handling and warehousing) as well as the costs for their production or processing to their final form.

The previously analysed and processed forecasts are gathered in an input file used for the next step which is the calculation of timesliding NPV integrals.

\section{Results of the code (Steps 5 and 6 )}

The results of the model are presented in this paragraph. The evolution path of NPVs as a function of ID time can be seen in Fig. 4

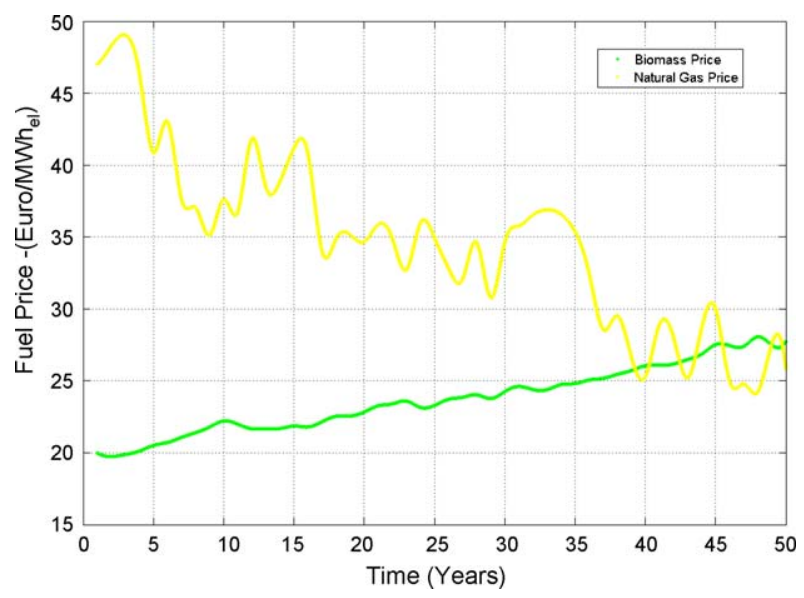

Fig. 3. Correlated fuel price forecasts.

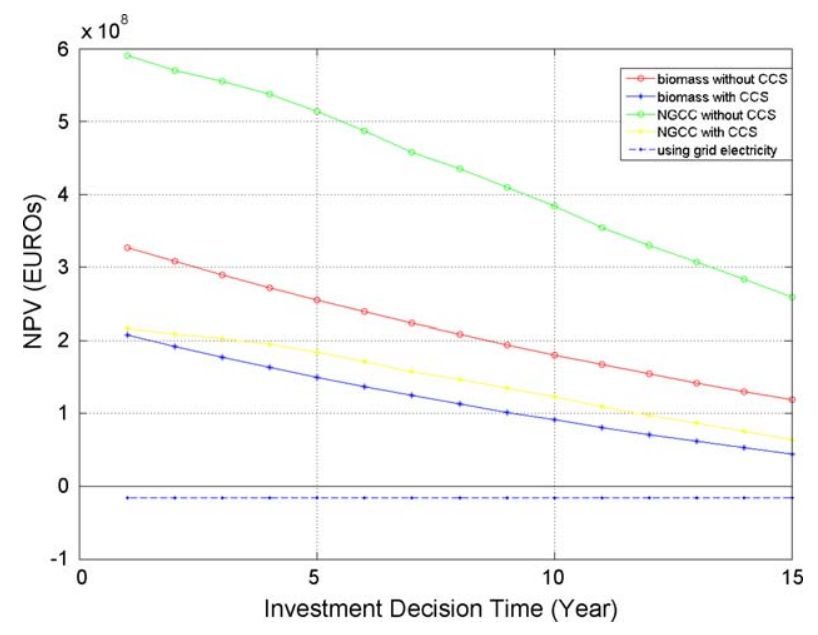

Fig. 4. NPV of different technologies as a function of ID time (ir $=8 \%$, EU-ETS).

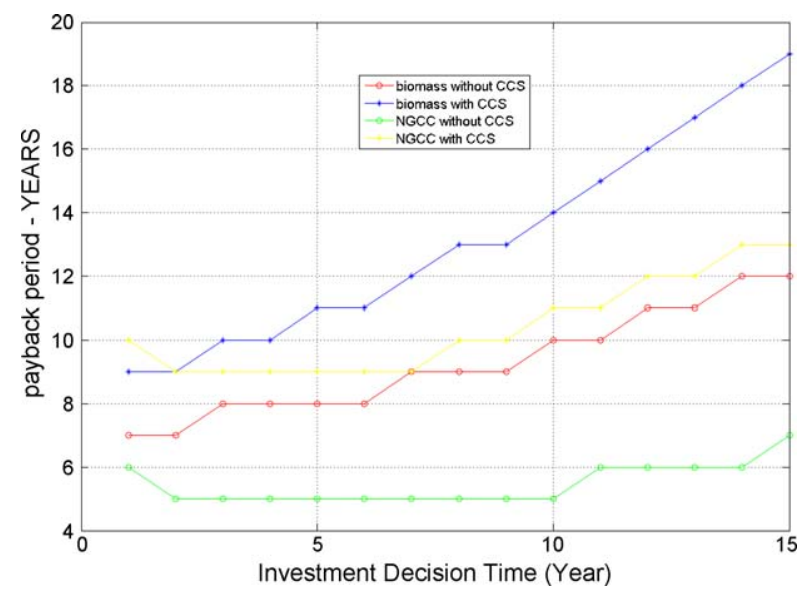

Fig. 5. Payback period of different technologies as a function of ID time (ir $=8 \%$, EUETS).

for each investigated technology. As stated before, in this basic scenario, an interest rate of $8 \%$ has been assumed while the EU-ETS is activated, meaning that there are no free $\mathrm{CO}_{2}$ allowances after the year 2012 .

The expected payback period for each power-production technology is shown in Fig. 5.

In order to assess the impact of EU-ETS implementation, the above graphs are recalculated assuming that the $\mathrm{CO}_{2}$ allowances

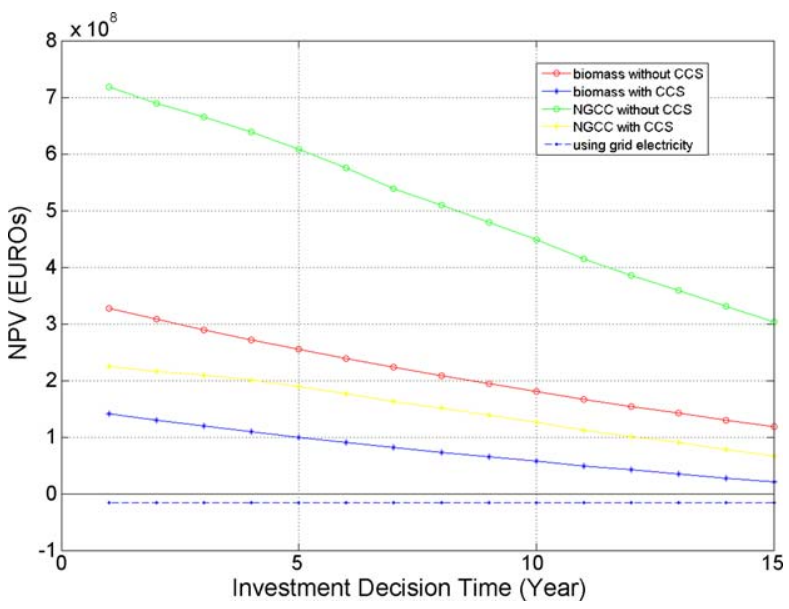

Fig. 6. NPV of different technologies as a function of ID time (ir $=8 \%$, no EU-ETS). 


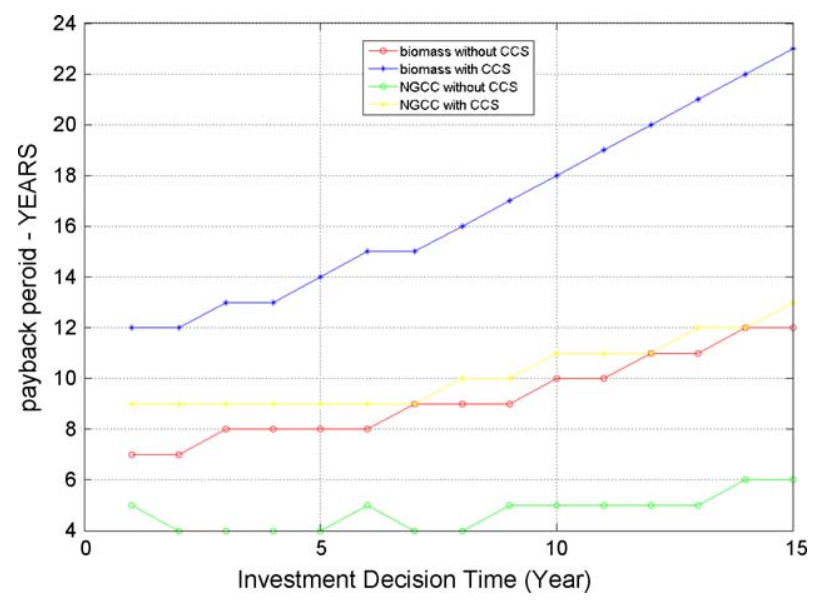

Fig. 7. Payback period of different technologies as a function of ID time (ir $=8 \%$, no EU-ETS).

are always free (their price is always equal to zero). In that case the evolution path of the different investments (NPVs as a function of ID time) is presented in Fig. 6 and the corresponding payback periods are presented in Fig. 7.

A slight NPV decrease compared with the results of Fig. 4 is noticed in all but biomass-fired plants, due to their neutral $\mathrm{CO}_{2}$ emissions.

The interest rate is a crucial parameter which greatly influences the economical efficiency of an energy-related project. In order to have an overview of investment decision modification due to interest rate variations, the graph in Fig. 8 is constructed presenting the expected NPVs for the different plants as a function of ID time but now assuming an interest rate $4 \%$. Some important alterations on investment decisions can be identified comparing Figs. 4 and 8 . Low interest rates might encourage potential investors to wait before actualising their business plans for almost 5 years, while - on the other hand - higher interest rates favor immediate investment decisions.

In Fig. 9, the financial balance of incomes and expenses as well as the cost breakdown are presented as a function of time. Nominal prices are estimated for every year of the operational life-time, for the basic scenario and the associated optimal ID time and technology, so that the major cost contributors may be recognised.

Finally in Fig. 10, the NPV is split in its contributors, either expenses or revenues, for the optimal technology (NGCC without CCS), as a function of ID time. The amortised fuel costs are

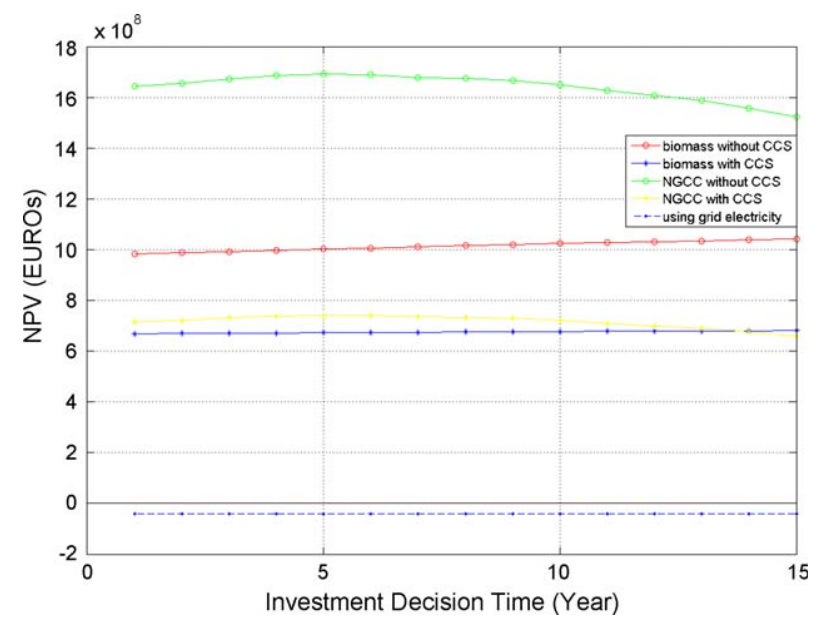

Fig. 8. NPV of different technologies as a function of ID time (ir $=4 \%$, EU-ETS).

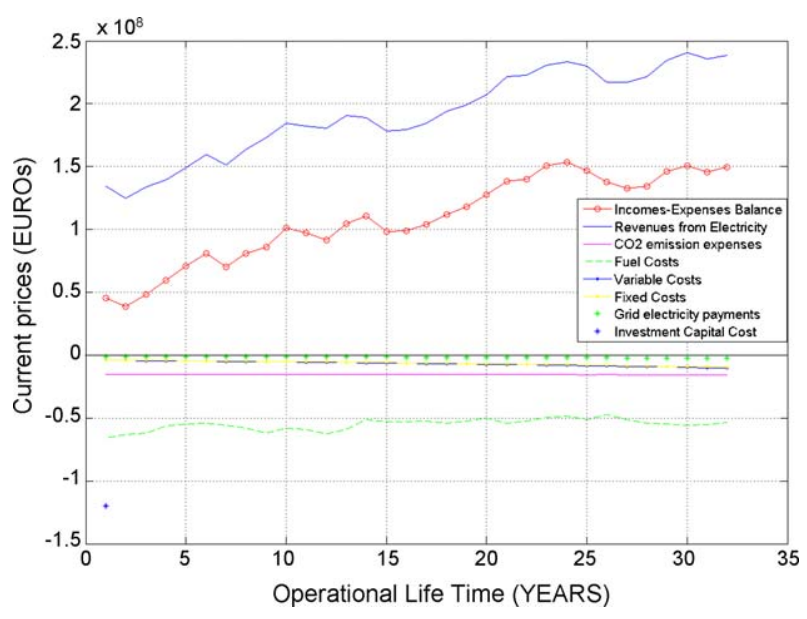

Fig. 9. Financial balance and cost breakdown for each year of operational life-time.

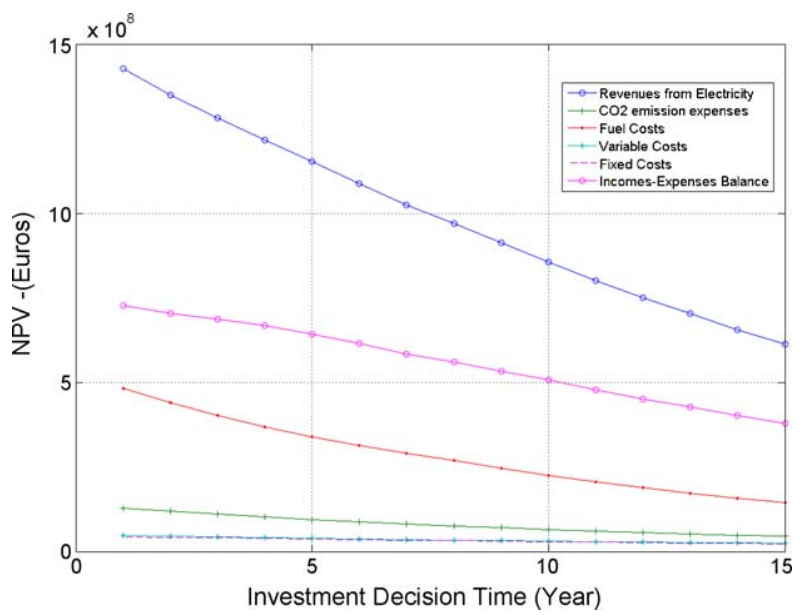

Fig. 10. NPV decomposition (NGCC, no CCS, ir = 8\%, EU-ETS, optimal ID time, no investment costs)

identified as the most significant cost factor compared to $\mathrm{CO}_{2}$ expenses and other fixed and variable costs.

\section{Discussion and conclusions}

In this work a time-dependent model has been presented, suitable for energy-related, private business strategies and decision making. Stochastic forecasting of prices with GBM, functional relationship of capital costs with time and integration within a real options frame, constitute its basic methodological structure. In the case study, the potential investors are in front of important investment options, including fuel selection, and timing for investment realisation. The conclusions of the study may be summarised in the following points:

- The expected NPV of NGCC plants without CCS is estimated to be higher, compared to the other types of power plants. The biomass-fired plants without CCS, appear to have lower NPV but not significantly higher than the other remaining technologies (i.e. biomass/CCS and NGCC/CCS).

- The negative NPV differences due to the installation of CCS are more significant on NGCC plants compared to the negative NPV differences appeared on the biomass-fired systems due to their respective capital and variable costs differences.

- Concerning an industrial user willing to invest on power production, all the investigated technologies appear to be 
financially promising (NPV $>0$ ) compared to the AS-IS situation. On the contrary, the NPV of remaining to the current status (i.e. paying for grid electricity) is obviously always negative.

- The fuel expenses constitute a dominating cost-factor for the NGCC plants while the costs due to the emissions trading are low but not negligible. The remaining cost factors (fixed operational costs, variable operational costs, etc.) are low for both plant types thus being insignificant for potential cost-killing policy. It is noted that the absolute values of revenues are significantly higher than those of fuel expenses, and consequently they are influenced more by higher interest rates.

- The risk of undertaking such a project is reflected on the assumed interest rate. With the currently existing conditions in the Greek Electricity market and assuming an interest rate of $8 \%$ (high levels of uncertainty for the future), the decision for an immediate investment on NGCC technology without CCS (ID $=1$ ) seems to be more interesting comparing to the option to wait. However, if a lower interest rate is assumed (4\%), waiting before investing might prove to be more profitable. In that case, the estimated optimal ID time is almost 5 years while the NPV improvement is small but not negligible (4-5\%) compared with an immediate investment decision. This is a direct effect of the electricity and fuel price volatile forecasts. As stated before, higher interest rates tend to reduce the far future electricity price forecasts, thus making future investments less promising for a potential industrial user.

- The price of $\mathrm{CO}_{2}$ allowances used in the study (about $21 € /$ ton $\mathrm{CO}_{2}$ ) does not seem to be able to promote the use of CCS technologies without further subsidies.

- The EU-ETS may reduce the expected NPV by 15-20\% in the cases of NGCC without CCS and biomass/CCS, while the NGCC/CCS plants are slightly affected. The biomass-fired plants without CCS, obviously remain unaffected by EU-ETS activation due to their neutral $\mathrm{CO}_{2}$ emissions.

- The influence on payback period follows a similar trend. The typical payback period for NGCC plants is almost 4-6 years assuming that the EU-ETS is inactive. With the assumption of EUETS activation, the payback period may be increased at least by 1 year. The payback period of biomass-fired plants remains unaffected by the implementation of EU-ETS.

From all the above it is concluded that a careful examination of existing fiscal conditions is a prerequisite for the final investors decision. Under the current conditions investing on either NG or biomass seems to be a profitable business. However, Power Sector is a rapidly changing business environment, severely influenced by emerging technologies and fuels. These innovations seem to spread a risk fear which usually discourages energy investments. Moreover, the recent legal status modifications concerning renewable energy and power sector deregulation may have a direct effect in the near future of domestic electricity market. Private business strategies and decision making should be in line with these changes as well as with the concept of environmental protection. Time-dependent investment analysis and "real options" might become useful tools for energy project assessments and further case studies may reveal interesting aspects on the economy of sustainability.

\section{Appendix A. The mathematical background for the forecasting tool}

Let us consider the following generic Wiener process given in stochastic differential equation (SDE) formulation:

$d \boldsymbol{X}_{t}=\boldsymbol{F}\left(t, \boldsymbol{X}_{t}\right) d t+\boldsymbol{G}\left(t, \boldsymbol{X}_{t}\right) d \boldsymbol{W}_{t}$ where:

- $\mathbf{X}$ is a state vector of process variables (for example, fuel or electricity prices) to simulate.

- $\mathbf{W}$ is a Brownian motion vector whose differential oscillates in a range of values generated by normal distribution.

- $\mathbf{F}$ is a vector-valued drift-rate function.

- G is a matrix-valued diffusion-rate function.

The drift and diffusion rates, $\mathbf{F}$ and $\mathbf{G}$, respectively, are general functions of a real-valued scalar sample time $t$ and state vector $\mathbf{X}_{t}$. Eq. $\left(1^{*}\right)$ is useful in implementing derived classes that impose additional structure on the drift and diffusion-rate functions. The derived class used in this study is the following:

GBM: The Geometric Brownian Motion Class whose general equation is:

$d \boldsymbol{X}_{t}=\mu(t) \boldsymbol{X}_{t} d t+\boldsymbol{D}\left(t, X_{t}\right) \boldsymbol{V}(t) d \boldsymbol{W}_{t}$

where:

- $\mathbf{X}_{t}$ is a state vector of process variables.

- $\mu(t)$ is the mean drift function derived from the historical data as a mean average of fluctuations.

- $\mathbf{D}\left(t, X_{t}\right)$ is a diagonal matrix-valued function. Each diagonal element of $\mathbf{D}$ is the corresponding element of the state vector raised to the corresponding element of an exponent $(\alpha(t))$, which is a vector-valued function: $\boldsymbol{D}\left(t, \boldsymbol{X}_{t}^{\alpha(t)}\right)$.

- $\mathbf{V}(t)$ is a matrix-valued volatility rate function.

- $d \mathbf{W}(t)$ is a Brownian motion vector (noise) differential which is equal to $\varepsilon \sqrt{d t}$ and $\varepsilon \in N(0,1)$.

\section{References}

[1] Rentizelas A, Tziralis G, Kirytopoulos K. Incorporating uncertainty in optimal investment decisions. World review of entrepreneurship. Management and Sustainable Development 2007;3(3/4):273-83.

[2] Kumbaroglu G, Madlener R, Demirel M. A real options evaluation model for the diffusion prospects of new renewable power generation technologies. Energy Economics 2008;30:1882-908.

[3] Ragland A, Stenzel W. Combined cycle heat recovery optimisation. In: ASME proceedings of 2000 international joint power generation conference; 2000

[4] Rhodes JS, Keith DW. Engineering economic analysis of biomass IGCC with carbon capture and storage. Biomass and Bioenergy 2005;29:440-50.

[5] International Energy Agency. Statistics for Greece; 2005. www.iea.org [08.12.08].

[6] Poullikkas A. An overview of current and future sustainable gas turbine technologies. Renewable and Sustainable Energy Reviews 2005;9:409-43.

[7] Maziasz PJ, Wright IG, Shingeldecker JP, Gibbons TB, Romanosky RR. Defining the materials issues and research for ultra-supercritical steam turbines. In: 19th annual conference on fossil energy materials; 2005.

[8] Craig KR, Mann MK. Cost performance analysis of biomass based integrated gasification combined-cycle (BIGCC) power systems. Report NREL/TP-43021657. US Department of Energy, National Renewable Energy Laboratory; 1996.

[9] Christou C, Hadjipaschalis I, Poullikkas A. Assessment of integrated gasification combined cycle technology competitiveness. Renewable and Sustainable Energy Reviews 2008;12:2459-71.

[10] Tatsiopoulos I, Tolis A. Economic aspects of the cotton-stalk biomass logistics and comparison of supply chain methods. Biomass and Bioenergy Journa 2003:24:199-214.

[11] Rentizelas A, Tolis A, Tatsiopoulos I. Logistics issues of biomass: the storage problem and the multi-biomass supply chain. Renewable and Sustainable Energy Reviews 2009;13:887-94.

[12] Trigeorgis L. Real options. Cambridge/Massachusetts: The MIT Press; 1996.

[13] Dixit A, Pindyck R. Investment under uncertainty. Princeton: Princeton University Press; 1994

[14] Laurikka H. Option value of gasification technology within an emissions trading scheme. Energy Policy 2006;34:3916-28.

[15] Laurikka H, Koljonen T. Emissions trading and investment decisions in the power sector-a case study in Finland. Energy Policy 2006;34:1063-74.

[16] Madlener R, Kumbaroglu G, Ediger V. Modelling technology adoption as an irreversible investment under uncertainty: the case of the Turkish electricity supply industry. Energy Economics 2005;27(1):139-63. 
[17] Junginger M, Faaij A, Turkenburg WC. Global experience curves for wind farms. Energy Policy 2005;33(2):133-50.

[18] Box G, Jenkins J, Reinsel G. Time series analysis: forecasting and control, third edition, Upper Saddle River, NJ: Prentice Hall; 1994.

[19] Baillie R, Bollerslev T. Prediction in dynamic models with time-dependent conditional variances. Journal of Econometrics 1992;52:91-113.

[20] McCullough BD, Renfro C. Benchmarks and software standards: a case study of GARCH procedures. Journal of Economic and Social Measurement 1998;25: 59-71.

[21] Shreve R. Stochastic calculus for finance II: continuous-time models. SpringerVerlag; 2004.

[22] Kloeden PE, Platen E. Numerical solution of stochastic differential equations. Springer, Berlin; 1999.

[23] Glasserman G. Monte Carlo methods in financial engineering. Springer-Verlag; 2004.

[24] Tiratsoo EN. Oilfields of the world. Scientific Press; 1973 [reference in Understanding Natural Gas].

[25] Brennard TP. Natural gas, a fuel of choice for China. Norwich: University of East Anglia; 2001. p. 81

[26] Rubin ES. Learning rates and future cost of power plants with $\mathrm{CO}_{2}$ capture. In: IEA International Workshop on Technology Learning and Deployment; 2007.

[27] Energy Information Administration. International energy outlook 2008; 2008. http://www.eia.doe.gov/oiaf/ieo/ [01.03.09].

[28] HTSO S.A. Hellenic transmission system operator, Statistics for the years 2001-2008; 2008. www.desmie.gr [13.12.08].

[29] PointCarbon. Carbon market indicator; 2008. http://www.pointcarbon.com [01.12.2008].

[30] Natural Gas Company of Attica. Statistics for the years 2001-2008; 2008. http://www.aerioattikis.gr/ [13.12.08].
Athanasios J. Tolis is a research engineer and has a degree in mechanical engineering from NTUA and a PhD on reverse logistics and investment optimisation from NTUA. His main areas of interest are related with economic aspects of renewable energy based power plants, energy economics, investment analysis, industrial forecasting and operational research. He has many years of academic experience since he contributes to the educational activities of the Sector of Industrial Management and Operational Research of the Mechanical Engineering School of NTUA (SIMOR/NTUA).

Athanasios A. Rentizelas holds a mechanical engineering degree from the National Technical University of Athens (NTUA), a MSc in operations management with distinction from UMIST, Manchester, UK and a PhD on supply chain optimisation focused on biomass from NTUA. He is currently a research engineer in the Industrial Management and Operational Research Sector of NTUA Mechanical Engineering School. His research interests and expertise lie in the areas of supply chain management, logistics, renewable energy sources, investment analysis, optimisation and quality management. He has been awarded various academic awards for his exceptional performance during his studies, as well as scholarships for postgraduate studies.

Ilias P. Tatsiopoulos is a professor in operations management and logistics at the Industrial Management and OR Section of the National Technical University of Athens (NTUA). He has been active for several years as a professional production engineer in both industrial and consulting firms and he served as a lecturer in management information systems at the Economic University of Athens. He studied mechanical and industrial engineering at NTUA (1978) and followed postgraduate studies at the TH Aachen (Germany) and the University of Lancaster (UK) under a NATO grant. He holds a PhD (1983) in operational research from the University of Lancaster. He is a member of the Senate of NTUA, Chairman of the Greek Institute for Production \& Operations Management and member of the board of the Hellenic Management Association (HMA). 